\title{
Análisis ético de la carta encíclica. Caritas in veritate
}

\author{
Yustinne Cárdenas Garay**
}

Recibido: 30 de mayo de 2015 • Aprobado: 30 de julio de 2015

\section{Resumen}

La encíclica Caritas in veritate vio la luz el 29 de junio de 2009, bajo el pontificado de Benedicto XVI. Originada como homenaje y prosecución de las enseñanzas de Pablo VI esbozadas en la carta encíclica Populorum Progressio, versa sobre el desarrollo humano integral de los pueblos en la caridad y la verdad. Con motivo de los 40 años de publicación de esta última encíclica, quiso estar lista para el año 2007, pero el intenso trabajo que requirió no permitió su expedición; sino hasta 2 años más tarde. La acogida de la carta fue bastante positiva, de lo cual dan fe dos hechos muy elocuentes: el mensaje de apoyo a la encíclica, titulado Doing the Truth in Love, firmado por 56 personalidades del mundo protestante evangélico estadounidense; y la consideración aparecida en el diario The New York Times, según la cual, tanto a progresistas como a conservadores la carta interpela a "pensar de nuevo sus posturas." (Blanco, 2009)ํㅣㄹ Incluso se llegó a sugerir el Papa Benedicto como

1 El recuento de estos sucesos nos los trae Pablo Blanco, que afirma: "en efecto, la ambición de la encíclica parece no conocer límites: pretende superar el esquema ideológico del mundo actual. Ross Douthat comentaba en The New York Times del 12 de julio que la encíclica no

* Este escrito es resultado de la investigación y profundización temática de la autora.

** Estudiante del Programa de Teología de la Universidad Santo Tomás. Correo electrónico: yusaeiou@gmail.com 
candidato al premio Nobel de Economía, "por haber sido el único que ha relacionado la crisis económica con la crisis demográfica y la caída de la natalidad" (Blanco, 2009).

Palabras clave: fraternidad, desarrollo humano, sociedad, ética económica, gratuidad.

\title{
Ethical analysis of the encyclical letter. Caritas in veritate
}

\begin{abstract}
The Caritas in Veritate encyclical was released on June 29, 2009, under Pope Benedict XVI. Originated as a tribute and continuation of the teachings of Paul VI outlined in the encyclical letter Populorum Progressio, it addresses the integral human development of peoples in charity and truth. On the occasion of the 40th anniversary of publication of this last encyclical, he wanted it to be ready for 2007, but the intense work required did not allowed its issuance; until two years later. The reception of the letter was quite positive, of which attest to two very eloquent facts: the message of support to the encyclical, entitled Doing the Truth in Love, signed by 56 personalities from the American evangelical Protestant world; and consideration that appeared in The New York Times, according to which both progressives and conservatives were challenged by the letter to "rethink their positions." (Blanco, 2009). Pope Benedict was even suggested as a candidate for the Nobel Prize in Economics "for having been the only one who has linked the economic crisis with the demographic crisis and the declining birthrate" (Blanco, 2009).
\end{abstract}

Keywords: Fraternity, human development, society, economic ethics, gratuitousness.

puede ser juzgada bajo el prisma de su coincidencia con ideas de izquierda o derecha, demócratas o republicanas, progresistas o conservadoras. "La nueva encíclica une la dignidad del trabajo con la santidad del matrimonio - continuaba-. Propugna la redistribución de la riqueza a la vez que subraya la importancia de un gobierno descentralizado. Conecta los atentados contra el medio ambiente con la destrucción masiva de embriones humanos". BLANCO Pablo. Caritas in veritate, en Nuestro tiempo, Revista cultural y de cuestiones actuales de la Universidad de Navarra. n.659, nov - dic 2009. Tomado del enlace: http://www.unav.es/nuestrotiempo/es/temas/ensayocaritas-in-veritate. 


\section{Analyse ethique de la lettre encyclique Caritas in veritate}

\section{Résumé}

La lettre encyclique Caritas in Veritate vit le jour le 29 juin 2009, sous le pontificat de Benedict XVI. Conçue comme hommage et poursuite des enseignements de Paul VI exposés dans la lettre encyclique Populorum Progressio, elle porte sur le développement intégral des peuples dans la charité et la vérité. A l'occasion des 40 ans de cette dernière encyclique, elle aurait dû être publiée en 2007, mais à raison du volume de travail que celleci représentait, elle a été publiée 2 ans après. La réception de la lettre fut très positive, ce qui est témoigné par deux faits très éloquents: le message de soutien à l'encyclique, intitulée Doing the Truth in Love, signé par 56 personnalités du monde protestant évangélique américain; et la considération parue dans The New York Times, selon laquelle progressistes aussi bien que conservateurs sont conduits à «repenser leurs positions» (Blanco, 2009). On a même proposé le Pape Benoît comme un candidat au Prix Nobel d'économie «pour avoir été le seul qui a lié la crise économique à la crise démographique et à la chute de la natalité» (Blanco, 2009).

Mots-clés: Fraternité, développement humain, société, éthique économique, gratitude.

La encíclica se estructura en seis capítulos, una introducción y una conclusión. En su respectivo orden estos capítulos tratan: el mensaje de la Populorum progressio; el desarrollo humano en nuestro tiempo; la fraternidad, el desarrollo económico y la sociedad civil; el desarrollo de los pueblos, los derechos y deberes, y el ambiente; la colaboración de la familia humana; y el desarrollo de los pueblos y la técnica.

\section{Contextualización socio-histórica de la carta}

Desde la encíclica misma podemos advertir qué contexto social acompaña su surgimiento: un contexto cuyo rasgo principal es el de una "humanidad en vías de unificación" (Benedicto XVI, 2009), "un mundo en progresiva y expansiva globalización" (Benedicto XVI, 2009). Es el fenómeno de creciente interconexión 
planetaria el que, en definitiva, distingue la situación social de Benedicto XVI con su Caritas in veritate, de aquella afrontada por Pablo VI en su Populorum Progressio, a la que nuestra encíclica busca honrar, retomando, siguiendo y actualizando sus enseñanzas, pues es la "Rerum novarum de la época contemporánea." (Benedicto XVI, 2009).

Partiendo de allí, hay que explicitar que el fenómeno de la globalización tiene consecuencias en todas las dimensiones humanas, inclusive en la espiritual. Así, en lo económico, que continúa teniendo por bien primero el comercio, se da "una creciente movilidad de los capitales financieros y los medios de producción materiales e inmateriales" (Benedicto XVI, 2009), dando lugar a que las actividades económicas ya no se circunscriban a un territorio geográfico delimitado: es lo que algunos han llamado deslocalización de los mercados y superación del ámbito de los Estados tradicionales (Martínez, ---). Mas persisten también rasgos provenientes de las décadas precedentes, como los altos aranceles, ya denunciados por Pablo VI, siguen impidiendo la inserción de los países pobres en el dinamismo económico global, dominado por los países ricos (Benedicto XVI, 2009).

A la par de esta movilidad financiero-económica-mercantil, se da el efecto contrario en lo político: las autoridades gubernativas siguen siendo predominantemente locales (Benedicto XVI, 2009). Hay sobresalto al constatar lo indefensos que están los gobiernos frente a estallidos de crisis económicas: lo débiles que se ven al lado de los agentes financieros, bancos y empresas, que concentran en sí una mayor acumulación y manejo de los capitales financieros globales, convirtiéndose, por ende, en los rectores de la gestión económica del planeta; constituyéndose en los señores de los bienes y actividades que integran la riqueza planetaria, los caudales disponibles para solventar las necesidades de la colectividad humana. El número 24 de la encíclica es especialmente claro en este aspecto donde, aleccionándose desde la misma crisis económica actual, hay que afirmar que a los poderes públicos se les da un papel como de azacán, de criado, al que se solicita solo cuando hay que corregir los errores y disfunciones de las intrepideces financieras. Si en las décadas anteriores las ideologías políticas condicionaron el desarrollo de los pueblos, y con la caída de los "bloques contrapuestos" se esperaba que el desarrollo económico y cultural pudiese aflorar (Benedicto XVI, 2009), hoy son las ideologías económicas las que están sometiendo a sí y determinando las pautas para el accionar político, cultural, social, espiritual: "los gobiernos, por razones de utilidad económica, limitan a menudo las libertades" (Benedicto XVI, 2009). 
En nuestra época, el Estado se encuentra con el deber de afrontar las limitaciones que pone a su soberanía el nuevo contexto económico-comercial y financiero internacional (Benedicto XVI, 2009).

La mayor proximidad y unidad actuales de la humanidad, como ya se mencionaba tiene efectos también en los ámbitos cultural, social, y espiritual. En lo cultural, el acercamiento y diálogo entre culturas está amenazado por ambos extremos del eclecticismo cultural y del rebajamiento de la propia cultura (Benedicto XVI, 2009); hay una extensión de legislaciones contrarias a la vida, fruto de una mentalidad antinatalista, que busca exportarse a otros Estados, aún a costa de condicionar las ayudas al desarrollo al hecho de que los países adopten medidas sanitarias de esta índole. (Benedicto XVI, 2009). También hay abuso en la protección del conocimiento, por parte de los países ricos, estancando el progreso de los países pobres, lo mismo que la persistencia de algunas costumbres y concepciones culturales frenan su desarrollo (Benedicto XVI, 2009). Hay una excesiva sectorización del saber y un cerrarse de las ciencias humanas a la metafísica (Benedicto XVI, 2009); se trata de la tendencia a relativizar la verdad que caracteriza a la cultura actual, bien desentendiéndose de ella, bien rechazándola (Benedicto XVI, 2009). Se difunde una visión restringida de la persona, que la cercena de su trascendencia, encerrándola en lo solo inmanente, dejándole desprovista de la esperanza, y de la fuerza de la caridad (Benedicto XVI, 2009) para desplegar su existencia en el mundo. "El positivismo jurídico y su correlato, el relativismo filosófico y moral, se encuentran en la base de tales contradicciones, que hoy no son menores que en tiempos de la Populorum progressio." (Cañizares, ---) El mismo estado de la de salud ecológica del planeta da cuenta de esta "crisis cultural y moral del hombre, cuyos síntomas son evidentes en todas las partes del mundo desde hace tiempo" (Benedicto XVI, 2009).

Entre los numerales 20 a 33, enmarcados dentro del capítulo segundo, encontramos una primera sección que hace un recorrido por las situaciones acuciantes de nuestros días, atravesadas transversalmente por la "ideología tecnocrática" que, si en lo cultural se deja sentir, se siente aún más en lo social. La confianza excesiva -hasta absoluta- en la técnica como adalid o panacea del desarrollo humano, y la negación de la moralidad de la técnica, que es producto humano, lleva a consideraciones tales como que el curso de las relaciones globales "tiene necesidad estructural de una cuota de pobreza y de subdesarrollo para funcionar mejor" (Benedicto XVI, 2009). La injusticia en el desarrollo de los pueblos persiste (Benedicto XVI, 2009), mientras surgen nuevas formas de colonialismo y dependencia de antiguos y nuevos países hegemónicos 
-manifestación de lo difícil del proceso de descolonización, en auge en tiempos de Pablo VI-; la corrupción y la ilegalidad afectan a países tanto ricos como pobres, malogrando las ayudas internacionales y el ejercicio efectivo de los derechos humanos; los flujos migratorios se posicionan como cuestión creciente en magnitud e importancia; y, en síntesis, "se sigue produciendo el escándalo de las disparidades hirientes", tanto a nivel global -entre países- como a nivel nacional, donde modos de vida derrochadora contrastan con condiciones de miseria deshumanizadora (Benedicto XVI, 2009). En el ámbito religioso asistimos al espectáculo de dos extremos: la promoción del ateísmo o de la indiferencia religiosa y el terrorismo de inspiración fundamentalista (Benedicto XVI, 2009).

Cabe resaltar que también entre los numerales 61 a 67 , pertenecientes al capítulo quinto, se realiza un examen de las distintas problemáticas concernientes a la educación, el turismo, las migraciones, el trabajo, los sindicatos, la producción y el consumo; hasta llegar a la propuesta de una "verdadera Autoridad política mundial" ya esbozada por Juan XXIII (Benedicto XVI, 2009). Es de gran importancia también la cuidada reflexión sobre la naturaleza y el medio ambiente, expuesta en el capítulo cuarto. En resumen podemos decir que la Caritas in veritate se escribe "en medio de la compleja encrucijada en la que se encuentra la humanidad entera tan ampliamente globalizada y sujeta a tan profundos cambios sociales, culturales y humanos, y en plena crisis económica mundial" (Cañizares, s.f.).

\section{Temas fundamentales}

El gran tema de la encíclica es la ética económica: quizá debido a la crisis económica que en ese momento era mucho más novedosa y alarmante, pero más aun por el papel que ha alcanzado lo financiero-mercantil en las dinámicas mundiales actuales y, por tratarse del tema del desarrollo de los pueblos, donde el factor económico es sin duda de gran relevancia, sin desconocer la importancia de los factores políticos, culturales y espirituales -como la caridad en la verdad lo demuestra-. La encíclica apuntará la necesidad de volver a traer a escena la relación irrenunciable entre economía y ética, o la moralidad de la economía pues, contrario a lo que la ideología tecnocrática postula diciendo que invertir es un hecho meramente técnico, "toda decisión económica tiene consecuencias de carácter moral" (Benedicto XVI, 2009).

La carta encíclica de Benedicto XVI tiene como elemento más recurrente la denuncia. En el camino de "profunda reflexión" (Benedicto XVI, 2009) que 
el Papa propone a todos los hombres de buena voluntad para corregir las desviaciones y disfunciones de los actuales modelos económicos mundiales, para reencontrar un humanismo nuevo, para fundar un futuro mejor y para permitirle al hombre moderno hallarse a sí mismo, y del que él mismo es ejemplo con la reflexión desarrollada en esta carta, se encuentra con múltiples falacias, reduccionismos, empobrecimientos, encerramientos e instrumentalizaciones con las que se manipula y somete al hombre (Benedicto XVI, 2009). Si se quiere un desarrollo humano integral, que es la apuesta y exigencia de la iglesia, no se pueden admitir estas ideologías que roban al hombre una realización plena al esconderle o mutilarle de la verdad, de la caridad, de la trascendencia.

Otro eje transversal de la encíclica es el replanteamiento de las dinámicas económicas globales: la exigencia de nuevos modelos y modos de ejercicio económico, nuevas concepciones de empresa, nuevas soluciones ante las hirientes desigualdades, hasta -si es necesario- la consecución de un nuevo orden económico productivo, que permita lograr el desarrollo efectivo de los pueblos (Benedicto XVI, 2009). Si bien la denuncia es abundante y contundente -no escatimando por lo que puede producir en las sensibilidades de los afectados-, al mismo tiempo abunda en propuestas (Benedicto XVI, 2009). Así por ejemplo, plantea la adopción del crédito cooperativo, del "principio de la gratuidad" y de la "lógica del don", concebir el beneficio para el bien de los hombres y de los pueblos, y no de manera individualista, lo cual estaría comprendido en nuevos modelos económicos con márgenes de gratuidad.

Por último, y como la propuesta de la iglesia para un verdadero desarrollo humano y lo que posibilite un replanteamiento de las dinámicas económicas globales servidoras a este fin, es el redescubrimiento de valores, la recuperación de los verdaderos sentidos de la libertad, de la caridad y de la verdad, que se han entendido incorrectamente y han sido asumidos así, sin una reflexión profunda y crítica. Es allí donde se enmarca la caridad en la verdad: la caridad, con toda la fuerza para alimentar, sostener y enaltecer las labores y esfuerzos por el bien y desarrollo de los hombres y pueblos, sin la cual el saber es estéril; y la verdad como iluminadora del amor, para guiarle y permitirle la inserción en los ámbitos universales, al poder dialogar con la universalidad de actores, salvando así a la caridad de una circunscripción en ámbitos limitados de relaciones de corto alcance.

Como se decía al comienzo de este trabajo, la carta analiza críticamente varios de los asuntos que hoy día plantean serias dificultades y que exigen urgentes reformas y respuestas. Sin embargo, todos ellos se encuentran atravesados 
por las diagonales que hemos enunciado anteriormente $y$, para tratarlos en detalle basta con remitirse a los numerales de la encíclica, ya relacionados a pie de página.

\section{Implicaciones para la moral social}

Concebir al hombre según la mentalidad tecnicista, hoy en expansión, que hace coincidir la verdad con lo factible y estipula como único criterio de verdad la eficiencia y la utilidad, conduce a negar automáticamente el desarrollo. "En efecto, el verdadero desarrollo no consiste principalmente en hacer." (Benedicto XVI, 2009) Pues, como también apunta Xavier Zubiri la vida humana, el ser histórico, no se trata de hechos puntuales, aislados y cerrados, sino que el ser histórico se trata de vocación: del porqué y para qué de los hechos. Por eso, si queremos un verdadero desarrollo de los hombres y de los pueblos, hay que denunciar y rechazar visiones reduccionistas como este utilitarismo, sino que, lo único que puede desarrollar íntegramente a la persona es "una razón abierta a la trascendencia" (Benedicto XVI, 2009), que es la única posibilidad de satisfacer el anhelo de "ser más" presente en todo corazón humano, y fuente de la fuerza espiritual y moral indispensable para comprometerse en el desarrollo humano integral. (Bnedicto XVI, 2009) Un inmanentismo tal es insostenible cuando todos los hombres tienen experiencia de tantos aspectos inmateriales y espirituales de su vida. "El vacío en que el alma se siente abandonada, contando incluso con numerosas terapias para el cuerpo y para la psique, hace sufrir. No hay desarrollo pleno ni un bien común universal sin el bien espiritual y moral de las personas, consideradas en su totalidad de alma y cuerpo" (Benedicto XVI, 2009).

Otra implicación en la moral social tiene la visión individualista del hombre, también integrada en la ideología tecnocrática, que amputa la dimensión relacional de la persona. En lo económico, y en lo político se deja sentir con más fuerza esta visión pues las actividades en estos ámbitos se dirigen por una lógica del propio beneficio y de una exclusión total de la gratuidad, del don, de la reciprocidad y fraternidad con otros. Consecuencia de este reduccionismo es la no realización integral de la dignidad humana, pues es evidente la naturaleza asociativa del hombre. En esa línea encontramos el planteamiento zubiriano de la religación, o reconocimiento de que se está ligado a otros, de que no se es una existencia aislada y en ese sentido autosuficiente; reconocimiento que encamina hacia la apertura. En el numeral 53 de nuestra carta encíclica también se deja claro, y se muestra cómo es producto de la hechura a semejanza de la Trinidad: 
“El hombre está alienado cuando vive solo o se aleja de la realidad, cuando renuncia a pensar y creer en un Fundamento[125]. Toda la humanidad está alienada cuando se entrega a proyectos exclusivamente humanos, a ideologías y utopías falsas[126]": la sociedad necesita de verdad y amor y el cristianismo es la religión de la verdad y del amor, por este motivo la mayor contribución que la Iglesia puede hacer al desarrollo es anunciar a Cristo, la Verdad encarnada, muerta y resucitada por amor (Blanco, 2009).

Surge una cuestión bien curiosa, que se bifurca en dos: la calidad de producto, o, mejor aún, la "creaturalidad". Si por una parte, el hombre no se reconoce dependiente de un Absoluto superior a sí, lo cual es especialmente evidente en el campo moral, por otra absolutiza realidades inmanentes e inferiores a sí, como la técnica y el mercado. Examinemos esto segundo. Ya desde la sociología del conocimiento -si es que no se quiere partir de la enseñanza cristiana- se verifica que la sociedad es producto del conocimiento humano. Como producto humano, tiene un quién detrás de sí: es decir, no puede considerarse como un "algo" meramente objetivo, neutro moralmente, sino que al surgir de un quién, que tiene una subjetividad particular, ha sido producido por una razón de este quién. Por tanto, si de la sociedad, que es producto humano, podemos decir esto, se aplica entonces -mediante un silogismo simple- a todo producto humano, y entre ellos encontramos la técnica y la economía. Repitámoslo en palabras del Papa: "la técnica nunca es sólo técnica. Manifiesta quién es el hombre y cuáles son sus aspiraciones de desarrollo, expresa la tensión del ánimo humano hacia la superación gradual de ciertos condicionamientos materiales." Por tanto las exigencias de la Caritas in veritate sobre el replanteamiento de la economía global con sus dinámicas, y el incesante llamado al ejercicio de nuevas formas y modos de actividad financiero-mercantil, tienen completo sustento ya que, el hombre puede intervenir en que él ha producido.

Lo contrario a esta absolutización de la técnica, propia de la ideología tecnocrática, es la "pretensión prometeica" del hombre: si ante el producto de sus manos el hombre se humilla, inclina y somete, ante Dios se subleva, se levanta y ensoberbece (Is 2, 8). Los prodigios de la tecnología -sin ser malos en sí mismoshan sido utilizados para dar la ilusión de que la humanidad puede recrearse a sí misma (Benedicto XVI, 2009))², del creer haber desvelado cualquier misterio, pues se ha llegado a la raíz de la misma vida, de una cultura del desencanto total (Benedicto XVI, 2009), y, en fin, de una ilusión del absolutismo del hombre.

2 Otro tanto ocurre en el campo económico, con "los prodigios de las finanzas". 
Se trata de la lucha entre el absolutismo de la técnica y la responsabilidad moral (Benedicto XVI, 2009). Estamos ante la cuestión fundamental: si el hombre es un producto de sí mismo o si dependen de Dios. La toma de partido por la primera postura está ya siendo hecha, y cristaliza bien en el tecnicismo. Pero lo cierto es que "el desarrollo de la persona se degrada cuando ésta pretende ser la única creadora de sí misma", y de ello hay múltiples y patentes testimonios: desde la explotación sin reglas de la tierra (Benedicto XVI, 2009), pasando por el abuso a los hombres y pueblos pobres -violando así el mandamiento divino del amor y siguiendo sólo una ciega e irreflexiva avaricia-, hasta el creciente índice de suicidios y desequilibrios mentales, preeminentes en los países más desarrollados y llenos de bienestar y "apertura" cultural.

La propuesta del Papa, y de la iglesia se dirige sobre todo en esta dirección, respecto al modo de concebir (Benedicto XVI, 2009): "en efecto, mucho depende del sistema moral de referencia." (Benedicto XVI, 2009) Es un imperativo de la caridad de Cristo el volver a iluminar a los hombres respecto a las falacias que les encaminan a la pérdida de las posibilidades de una existencia plena, en la libertad y la verdad. La moralidad no es, entonces, una coacción a la libertad sino su potenciadora y auxilio en tanto la libra de ser presa de trampas que la amarren y encierren. "La libertad humana es ella misma sólo cuando responde a esta atracción de la técnica con decisiones que son fruto de la responsabilidad moral." Toda decisión, en aún en el ámbito político, económico y técnico, tiene una responsabilidad moral. De ahí la necesidad apremiante de una formación para un uso ético y responsable de la técnica (Benedicto XVI, 2009).

La crisis económica actual deja al descubierto que no hay orden en el supuesto orden económico actual. No hay orden, ni equilibrio, ni igualdad, porque estas tres características de las relaciones sociales bien orientadas, se sostienen si hay ejercicio del servicio: la mentalidad económica vigente lo último que contempla es el servicio - ¿lo contempla siquiera?-, sino que por el contrario, la actual economía es el ambiente por antonomasia de la exacerbación del individualismo, del egoísmo, de la voracidad, de la codicia: es como un traslado de la depredación que se ve en la vida salvaje de las fieras a "la sofisticada vida humana"; podemos hablar, realmente, de salvajismo económico, entonces, ¿somos salvajes económicos? Estamos presenciando, asistiendo a una economía in-civilizada, con el imperativo de civilizarla (Benedicto XVI, 2009) -más aún si somos cristianos-: "el mercado no es ni debe convertirse en el ámbito donde el más fuerte avasalle al más débil" (Benedicto XVI, 2009). 
A partir de la categoría bíblica de la justicia permítasenos decir una palabra. Desde la justicia radical podemos constatar cómo hoy los poderosos se amparan, se ciñen en la legalidad, aún los mismos gobiernos legislan leyes que dan potestades desbordadas a los agentes financieros, perjudicando a los más débiles, que son quienes, ante su situación de desigualdad deberían ser a quienes favorezca la ley para igualarlos frente a los que se encuentran en posiciones económicas, políticas o sociales más aventajadas. Desde la justicia/misericordia se ve que hay que trabajar en la justicia horizontal (conmutativa), pero sobre todo en la vertical (distributiva), donde brille el principio de la subsidiariedad y la misericordia para hacerse cargo del excluido, de aquel que "no cuenta", que tiene poco valor para el mundo; pues no se trata de "dar a un vago", sino de igualar a aquel a quien se le ha privado de los justos medios, oportunidades y derechos.

Desde la axiología y la ética económica podemos leer que, respecto al tener, a cómo organiza una sociedad sus bienes, el actual "orden" económico se encuentra muy desviado: ¿qué necesidades prioriza su actividad económica?: ya vimos que se trata del flujo de capitales desregularizado, solo accesible y benéfico para los agentes económicos enormes y pocos; ¿cómo produce lo que produce, son dignas las condiciones de trabajo?: "la falta de respeto de los derechos humanos de los trabajadores es provocada a veces por grandes empresas multinacionales y también por grupos de producción local" (Benedicto XVI, 2009); y ¿quiénes son los destinatario de la producción, para quiénes produce?: "la riqueza mundial crece en términos absolutos, pero aumentan también las desigualdades. En los países ricos, nuevas categorías sociales se empobrecen y nacen nuevas pobrezas." En suma, no se produce con vistas a redistribuir la riqueza o contribuir al desarrollo de los más rezagados en su economía, sino con miras al mantenimiento del status quo de las potencias e, incluso de una rivalidad entre los países pujantes, buscando superar a sus competidores aunque implique destinar a este fin los recursos para contribuir con los países pobres.

Son ciertamente muchas las implicaciones que pueden para la moral social, pero nos limitaremos a terminar ahora con dos breves consideraciones finales. Si Jesús incomodaba políticamente porque desenmascaraba el pecado, y no sólo el individual sino también el social, ¡qué gloria para la iglesia porque hoy ella incomoda tanto, al denunciar el pecado, tanto personal como social! Actualmente se quiere ignorar o eliminar la moralidad, ¿será por el compromiso que se adquiere al emitir un juicio moral?, pues allí se ve el paradigma antropológico que está a la base de lo emitido. Sea como sea, frente a un panorama 
tan recargado como el que presenta nuestro contexto, aparece otra categoría bíblico-teológica: la justicia/esperanza, caracterizada por el dinamismo y el discernimiento, nuestra esperanza cristiana no es una esperanza sufrida, sino una espera alegre, porque ya tenemos anticipos de es Reino que es nuestra esperanza. Ya los esfuerzos de los justos están construyendo los cimientos de verdaderas estructuras de gracia.

La doctrina social de la iglesia tiene por opción clara y permanente la defensa de todo hombre, especialmente de los más débiles. La Rerum Novarum exponía la potencialidad transformadora de la fe para cambiar la sociedad desde sus cimientos, por la entrega toda de sí mismo a los demás (León XIII, 1891); la "Rerum Novarum de nuestros días" hacía este llamamiento final: “a los seglares les corresponde con su libre iniciativa y sin esperar pasivamente consignas y directrices, penetrar de espíritu cristiano la mentalidad y las costumbres, las leyes y las estructuras de la comunidad en que viven" (Pablo VI, 1967). La vida teologal tiene por consecuencia directa la caridad política: la visión contemplativa, que entiende el mundo y la historia dentro de la dinámica divina de la Creación y de la Redención, no deja lugar a divisiones espiritualistas entre el campo de la fe y el de la política. Porque

El evangelio no presenta una ley de la caridad para las personas particulares y otra ley distinta para los Estados y las naciones, que en definitiva están compuestas por hombres particulares (Benedicto XV, 1920).

\section{Aplicación pastoral}

Existe ya una propuesta en la iglesia peruana de "Versiones populares" de las encíclica para presentarlas en un formato sencillo que las ponga al alcance de nuestras comunidades cristianas ${ }^{3}$. La versión se compone por una síntesis de cada capítulo con "preguntas para la reflexión” al final de cada capítulo.

Otra manera de transmitir los contenidos de la encíclica puede ser a través del teatro. Tratando temas tan actuales como hemos visto, no serán difíciles de representar. Y allí debe aparecer un personaje que sea la Voz de la iglesia respecto a aquellas situaciones, y las manos de la iglesia. Sí: aún puede hacerse

3 Puede consultarse siguiendo el enlace: http://www.iglesiacatolica.org.pe/cep_especiales/2010/xi-semanasocial/xiss_documentos/version-popular-caritasinveritate.pdf 
a modo de mímica, mostrando cuáles son las acciones que desde la iglesia se exigen y defienden ante las laceraciones sociales de nuestro mundo.

También puede trabajarse en la oración y reflexión comunitaria. Leyéndose, con el acompañamiento de un teólogo y/o fiel adecuadamente preparado, discutirse uno, dos, tres o los numerales que sean convenientes para el tiempo que se disponga para el encuentro, y en base a eso, realizar la oración comunitaria para, con la acción de gracias y la súplica, pedir a Dios, Padre de toda la familia humana, su Providencia y Espíritu para trabajar por el desarrollo integral de los hombres y de los pueblos.

Otro modo de trabajarlo, para que no sea sólo la lectura de los numerales, puede ser la asignación de uno o varios numerales a x o y persona(s), con el reto de que lo expongan al grupo mediante una forma creativa, distinta a la lectura (representándolo, dibujándolo, relatándolo en forma de novela, o como poesía, haciendo una dinámica que remita a la temática principal, etc.)

Puede ser especialmente clarividente trabajar esta carta encíclica con los jóvenes, y quizás más aún con los universitarios, en pleno proceso de búsqueda de la edificación de un futuro mejor.

Pudiendo parecer obvio, puede que no debamos dar por supuesto del conocimiento de los presbíteros sobre estas temáticas de doctrina social. Por tanto, podríamos pensar también en la inclusión del clero dentro del público a quien se dirija la transmisión de los contenidos de las encíclicas.

Sin embargo, valga decir que fieles -y no fieles- de todas las edades pueden ser destinatarios idóneos de la transmisión de este mensaje magisterial: los niños, mediante formas debidamente adaptadas a su sentir y comprensión; los adultos, que llevan sus vidas inmersos en las dinámicas socio-económicopolítico-culturales que tocan la encíclica, para que puedan referenciar desde un nuevo punto de vista sus quehaceres y cuanto los rodea; y los ancianos, que con su sabiduría y disposición pueden trabajar también comprometidos por la consecución de aquello a que nos urge la caridad de Cristo, y guiar a los más jóvenes que ellos en esta labor. Aún, puede pensarse en la socialización del contenido de la Caritas in veritate, y en general de la doctrina social de la iglesia, con los alejados de la fe, los indiferentes, los no creyentes, y los ateos y opositores de la fe: la doctrina social como una pedagoga, como un preambula fidei hacia la contemplación del verdadero rostro de Cristo. 


\section{Referencias}

Benedicto XV, (1920). Carta enc. Pacem Dei (23 mayo 1920). Puede consultarse siguiendo el enlace: http://www.iglesiacatolica.org.pe/cep_especiales/2010/xi-semanasocial/ xiss_documentos/version-popular-caritasi. Recuperado: 18/03 /2015.

Benedicto XVI, (2009). Carta enc. Caritas in veritate (29 junio 2009).

Blanco, P. (2009). Caritas in veritate, en Nuestro tiempo, Revista cultural y de cuestiones actuales de la Universidad de Navarra. n.659, nov - dic 2009. Tomado del enlace: http://www.unav.es/nuestrotiempo/es/temas/ensayo-caritas-in-veritate. Recuperado: 12/03/2015.

Cañizares A. (s.f.). Caritas in veritate. Recopilado por la Conferencia Episcopal Española. Tomado del enlace: http://www.conferenciaepiscopal.es/documentos/ benedictoXVI/enciclica/canizarez.pdf. Recuperado: 18/03/2015.

León XIII, (1891). Carta enc. Rerum Novarum (15 mayo 1891).

Martínez camino, J. A. (s.f.). Sin dios, ni fraternidad ni desarrollo. Primera lectura de Caritas in veritate de Benedicto XVI. Recopilado por la Conferencia Episcopal Española. Tomado del enlace: http://www.conferenciaepiscopal.es/documentos/ benedictoXVI/enciclica/martinez.pdf. Recuperado: 15/03/2015.

Pablo VI, (1967). Carta enc. Populorum Progressio (26 marzo 1967). 